\title{
Sickling Times of Individual Erythrocytes at Zero $\mathrm{PO}_{2}$
}

\author{
Harold S. Zarkowsky and Robert M. Hochmuth \\ From the Edward Mallinckrodt Department of Pediatrics, Washington \\ University School of Medicine and the Department of Chemical Engineering, \\ Washington University School of Engineering and the Division of Hematology \\ and Oncology at St. Louis Children's Hospital, St. Louis, Missouri 63110
}

A в STR A C T A rapid-reaction parallel-plate flow channel was used to study the kinetics of erythrocyte sickling upon sudden deoxygenation with sodium dithionite. The erythrocytes were recorded on 16-mm film or video tape and visually tracked in time. Sickling was identified by morphologic criteria. At the flow rate used in these studies, the rate of sickling was a reactionlimited process. There was no loss of cellular deformability or membrane flicker before the onset of sickling. Typical sickling times for sickle $(S S)$ cells and trait $(A S)$ cells at room temperature in isotonic buffer were 2.0 and $70 \mathrm{~s}$, respectively. Increasing the buffer osmolality resulted in shorter sickling times and under hypctonic conditions the time required for sickling was prolonged. Between $\mathrm{pH} 6.4$ and 7.0 there was little change in the time required for $50 \%$ of the originally discoidal cells to sickle $\left(t_{50}\right)$; whereas a marked increase in $t_{50}$ occurred between $\mathrm{pH} 7.4$ and 7.6. Whole populations of $A S$ and $S S$ erythrocytes were separated into three fractions after centrifugation. The $t_{50}$ of the fractions progressively decreased from top to bottom, which paralleled an increase in mean corpuscular hemoglobin concentration (MCHC). The $t_{50}$ decreased as the temperature was increased from $13^{\circ}$ to $34^{\circ} \mathrm{C}$. This temperature effect was more pronounced for cells that had osmotically induced reductions in MCHC. A two-step process for erythrocyte sickling is proposed: an initial lag phase, during which there is little or no change in internal viscosity, followed by a rapid phase of cellular deformation. The lag phase is altered by changes in $\mathrm{MCHC}, \mathrm{pH}$, and temperature.

This work was presented in part at the First National Symposium on Sickle Cell Disease, Washington, D. C., June 1974.

Dr. Hochmuth is the recipient of Research Career Development Award 5K04 HL 70612.

Received for publication 31 Jamuary 1975 and in revised form 9 May 1975.

\section{INTRODUCTION}

Studies on the time required for in vitro erythrocyte sickling have often failed to distinguish between diffusion-limited and reaction-limited processes. In the former, the time for sickling is limited by the time required to remove oxygen from the red cells. Ideally, measurement of sickling times should be made in a reaction-limited system, i.e., oxygen removal is completed much sooner than the gelation of sickle hemoglobin.

Visual $(1,2)$ and viscometric (3) determinations of erythrocyte sickling in diffusion-limited systems have yielded sickling times between 1 and $30 \mathrm{~min}$. Padilla et al. (4) observed individual sickle erythrocytes during a 1-h period of deoxygenation, and defined the sickling time as the interval between loss of red cell membrane flicker and the completion of deformation into the sickle shape. In their studies, the sickling time was between 10 and $15 \mathrm{~s}$. Messer and Harris (5) used a continuous flow rapid-reaction apparatus to accomplish sudden deoxygenation with dithionite. In contrast to the studies of sickling in diffusion-limited systems, they observed a decrease in filterability of sickle erythrocytes within $0.12 \mathrm{~s}$ after sudden deoxygenation, which suggested that deoxygenation and altered rheology occurred almost simultaneously. However, morphologic distortion could not be detected for several seconds after sudden deoxygenation. On the other hand, Rampling and Sirs (6), using a continuous flow rapid-reaction device, which allowed rapid cell fixation, observed the production of "bizarre-shaped" erythrocytes within $0.03 \mathrm{~s}$ after the removal of oxygen.

The purpose of the present study was to determine the sickling time of individual erythrocytes at zero $\mathrm{Po}_{2}$ in a reaction-limited system that did not require fixation of red cells for morphologic analysis. To this end, a rapid-reaction parallel-plate flow channel was designed that allowed the observation of individual erythrocytes

The Journal of Clinical Investigation Volume 56 October 1975·1023-1034

1023 
throughout deoxygenation and the sickling process. In the course of this research, a criterion for the determination of the sickling time for an individual cell was established; and the effect of osmolality, $\mathrm{pH}$, temperature, and mean corpuscular hemoglobin concentration $(\mathrm{MCHC})^{1}$ on the kinetics of erythrocyte sickling was studied.

\section{METHODS}

Blood was collected in heparinized Vacutainer tubes (Becton, Dickinson \& Co., Rutherford, N. J.) from individuals homozygous $(S S)$ or heterozygous $(A S)$ for sickle hemoglobinopathy. Hemoglobin electrophoresis was performed on cellulose acetate, and the proportion of hemoglobins A and $\mathrm{S}$ in $A S$ individuals was quantitated by elution and an optical density reading at $410 \mu \mathrm{m}$. Hemoglobin $\mathrm{F}$ was measured by the alkali resistance method of Singer et al. (7) and was less than $6 \%$ in all $S S$ patients studied. The blood was centrifuged in a Lourdes centrifuge (Lourdes Instrument Corp., Old Bethpage, N. Y.) at $4^{\circ} \mathrm{C}$ and $1,500 \mathrm{~g}$ for $10 \mathrm{~min}$ and the plasma and buffy coat were discarded. The red cells were washed twice in phosphate-buffered saline (PBS) : $7.275 \mathrm{~g} \mathrm{NaCl}, 3.143 \mathrm{~g} \mathrm{Na}_{2} \mathrm{HPO}_{4}$, and 0.738 $\mathrm{g} \mathrm{KH}_{2} \mathrm{PO}_{4}$ in 1 liter distilled, deionized water. The standard PBS had a pH of 7.4 \pm 0.005 and an osmolality of $280-290$ mosmol/liter. The osmolality of PBS was altered by varying the concentration of $\mathrm{NaCl}$, and final osmolality measured with an Osmette Model 2007 freezing point depression osmometer (Precision Systems, Inc., Sudbury, Mass.). The $\mathrm{pH}$ of the PBS was adjusted with $\mathrm{HCl}$ or $\mathrm{NaOH}$ and measured with a model 125A Blood Gas Analyzer (Instrumentation Laboratory, Inc., Lexington, Mass.). An 8-10-ml suspension of red cells at a hematocrit of 0.2 $0.25 \%$ was prepared by suspending the washed cells in the appropriate $\mathrm{PBS}$ to which bovine serum albumin (BSA) $(1 \mathrm{~g} /$ liter $)$ and glucose $(1 \mathrm{~g} /$ liter $)$ were added.

Density separation of erythrocytes was performed in a Sorvall RC-2B centrifuge (Sorvall-Dupont Instruments, Sorvall Operations, Newtown, Conn.) at 15,000 rpm at $30^{\circ} \mathrm{C}$ for $60 \mathrm{~min}$, according to the procedure of Murphy (8). After centrifugation, the top, middle, and bottom thirds of the erythrocyte column were suspended in PBS, $\mathrm{pH} \mathrm{7.4,} \mathrm{and} \mathrm{then} \mathrm{processed} \mathrm{for} \mathrm{study} \mathrm{in} \mathrm{the} \mathrm{flow} \mathrm{channel.}$

Hematocrits were determined in an International Microcrit centrifuge (Damon/IEC Div., Damon Corp., Needham Heights, Mass.) spun for $10 \mathrm{~min}$. Hemoglobin was determined as cyanmethemoglobin. The MCHC was calculated from the hematocrit and hemoglobin values. All determinations were performed on the washed red cells suspended in aerated PBS.

Deaerated PBS was prepared by bubbling nitrogen gas through PBS until a $\mathrm{PO}_{2}$ of $1-4 \mathrm{~mm} \mathrm{Hg}$ was obtained (Model 125A Blood Gas Analyzer, Instrumentation Laboratory), and then adding sodium dithionite $\left(\mathrm{Na}_{2} \mathrm{~S}_{2} \mathrm{O}_{4}\right.$ : Matheson Coleman \& Bell, East Rutherford, N.' J.), 2.50 g/liter; a quantity which greatly exceeds the minimum critical value required to remove all oxygen in an oxygen-

${ }^{1}$ Abbreviations used in this paper: AS, heterozygous for sickle hemoglobinopathy; BSA, bovine serum albumin; ISC's, irreversibly sickled cells; MCHC, mean corpuscular hemoglobin concentration; PBS, phosphate-buffered saline; $S S$, homozygous for sickle hemoglobinopathy; $\bar{t}$, mean tran-

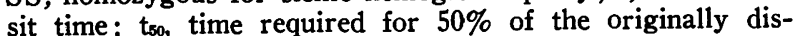
coidal cells to sickle. ated saline solution. (For comparison, note that the $\mathrm{Na}_{2} \mathrm{~S}_{2} \mathrm{O}_{4}$ concentration is $1.44 \times 10^{-2} \mathrm{M}$ while the concentration of oxygen in water at $1 \mathrm{~atm}$ at $23^{\circ} \mathrm{C}$ is $2.43 \times 10^{-4} \mathrm{M}-\mathrm{a}$ ratio of $60: 1)$. Deaeration of PBS before the addition of sodium dithionite minimized the formation of products of oxidation of dithionite, such as hydrogen peroxide. The $\mathrm{pH}$ and osmolality of the deoxygenated solution were adjusted to equal that of the suspending buffer. In one series of experiments, the dithionite concentration was reduced to $25,12.5,5$, and $2 \%$ of the "standard" ( $2.5 \mathrm{~g} /$ liter $)$ concentration.

Flow channel. A rapid-reaction parallel-plate flow channel shown in Fig. 1 was used to remove oxygen from sickle cells adhering to a glass cover slip that forms the top surface of the channel. The flow channel base plate shown in the figure is fabricated of $\frac{1}{4}$-in Plexiglas (Rohm and Haas Co., Philadelphia, Pa.). Three Becton-Dickinson three-way valves (Becton-Dickinson \& Co., Rutherford, N. J.) are threaded and screwed into the Plexiglas. A Teflon plug is inserted to insure an air-tight fit between the valves and the 16 -in ID inlet and outlet tubes. The channel itself is formed by placing a $500-\mu \mathrm{m}$ thick Parafilm gasket (American Can Co., New York) on the base plate, which just barely extends to encompass the inlet and outlet holes in the base plate. The dimensions of the channel formed by the gasket are $4.1 \times 0.95 \mathrm{~cm}$. The base plate-gasket-cover slip "sandwich" is secured with a stainless steel clamping plate that mounts on the Plexiglas base plate with bolts. The system was assembled completely under water. Before removal from water, all valves were closed to give a completely filled channel. Water was flushed through all valves and the inlet and outlet tubes in the base plate. Finally, the channel was carefully examined for any signs of air bubbles. The threevalve design (with upstream inlet and side valves and a downstream outlet valve-see Fig. 1) permits the flow of deoxygenated fluid past the channel inlet before flow through the channel is initiated. A $50 \mathrm{ml}$ Becton-Dickinson Luer-Lok syringe mounted in a Harvard VDC infusion pump (Model 2206, Harvard Apparatus Co., Inc., Millis, Mass.) was used to infuse deoxygenated PBS through the channel at a controlled rate. The regular plunger was replaced with a solid Plexiglas plunger fitted with an O-ring to insure an air-tight fit.

Experimental procedure. After assembly under water, the flow channel was flushed with $40-50 \mathrm{ml}$ of distilled, deionized water and then an equal volume of PBS. Care was taken not to introduce any bubbles during this procedure. The sequence for flushing was: $(a)$ flush through inlet valve with side stream and outlet valves closed, $(b)$ flush through inlet and side valves with outlet valve closed, and $(c)$ flush through channel (inlet and outlet valves open, side valve closed). All valves were closed immediately after flushing. Next a solution of $0.1 \%$ BSA in PBS was injected into the channel and allowed to remain there for 5-10 min to permit the BSA to absorb on the glass cover slip as well as other interior surfaces. Then, the cell suspension at the hematocrit of $0.2-0.25 \%$ was slowly injected into the (inverted) channel and the cells were allowed to settle onto the cover slip for 10-15 min. (In separate experiments with an inverted microscope, it was observed that essentially all of the cells adhered to the surface and remained there after flow was initiated.) The channel was attached to the microscope stage (Zeiss Universal Microscope, Carl Zeiss, Inc., New York, with phase contrast objectives) and connected to the $50-\mathrm{ml}$ infusion syringe containing the deoxygenated PBS with dithionite 


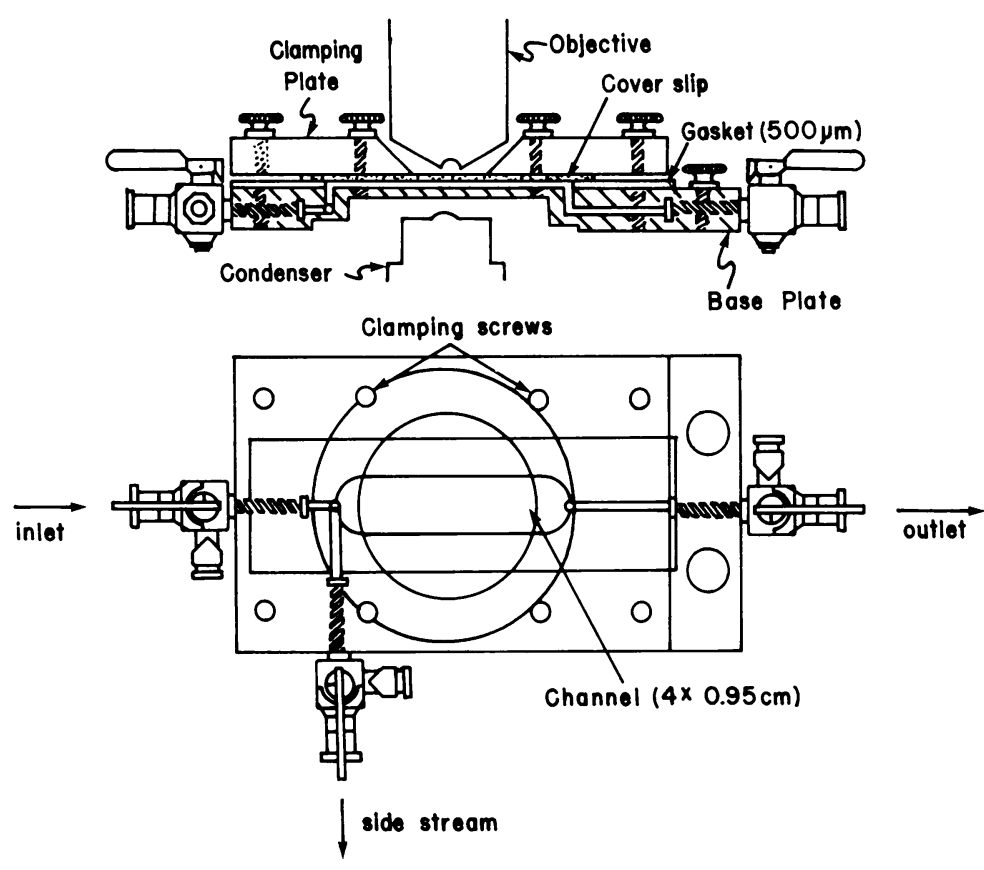

FigCre 1 Rapid-reaction parallel-plate flow channel. Side and top views of the flow channel are shown. The channel itself is formed by the Parafilm gasket, which covers the Plexiglas base plate, and glass cover slip, and is secured with a stainless steel clamping plate.

and the following flushing sequence was initiated: a slow 5 -min flush $(1 \mathrm{ml} / \mathrm{min})$ through the inlet and side outlet of the three-way upstream valve with side stream and outlet valves closed, and a slow flush through upstream and side valves for $1 \mathrm{~min}$ with outlet valve closed. ${ }^{2}$ Finally, the pump was stopped, the side valve closed, the outlet valve opened, and flow through the channel initiated by turning on the infusion pump.

The sickling process was recorded with either a $16-\mathrm{mm}$ Bolex camera (Paillard S.A., Sainte Croix, Switzerland) (on constant voltage power supply so that framing rate is constant) or a Javelin time-lapse videotape recorder (Model X-400, Los Angeles, Calif.) and Odetics timedate generator (Model G77, Anaheim, Calif.). The instant at which flow begins was readily observed since the cells adhering to the glass cover slip immediately deform into teardrop shapes (9). Because of the very small fluid shear stress in these experiments (about $1 \mathrm{dyn} / \mathrm{cm}^{2}$ ), only a small amount of cellular elongation occurred, no tethers were formed, and few, if any, cells were detached from the surface by the flow $(9,10)$. The time from the instant of initiation of flow was measured either by counting frames on the $16-\mathrm{mm}$ film (18 frames $=1.0 \mathrm{~s}$ ) or by noting the digital time reading (in 0.01 -s increments) recorded on the video tape and viewed on a television monitor.

With the $25 \times$ Planochromat dry phase contrast objective (Zeiss), a field of approximately 200-250 erythrocytes was recorded. Individual discoidal red cells were tracked in time. Irreversibly sickled cells (ISC's) were excluded because it was more difficult to appreciate their morphologic changes, and their sickling times appeared extremely rapid. In the $S S$ patients studied, the percentage of ISC's was less than $10 \%$. The sickling time was that time interval between the initiation of flow and onset of morphologic changes. Morphologic change was identifiegd by dis- tortion of the cell surface. At the completion of sickling (usually less than $0.5 \mathrm{~s}$ after onset), a variety of cell shapes was recognized-holly leaf forms, contracted forms with surface projections, and true sickled shapes-and the cell was very rigid in all cases; the latter was verified in some instances by increasing the flow rate and noting that no cellular deformation occurred. Since a cell's morphologic changes were readily reviewed by replaying the film or tape, any question concerning the onset of morphologic distortion was easily resolved. In calculating the percentage of cells sickling during any time interval, the total number of initially discoidal cells under observation was used. In all studies, the experiment was recorded until more than $75 \%$ of the cells had sickled.

To study deformability (9-11), the flow of deoxygenated PBS was oscillated by manually turning the speed control on the Harvard pump between zero and a maximum value at the rate of $0.5 \mathrm{cycle} / \mathrm{s}$. A $100 \times$ planachromat oil immersion phase contrast objective was used. From the 16-mm film, the maximum length of a particular cell during each cycle was measured before morphologic sickling and this length was compared to the undeformed (zero flow) length of the cell.

All studies were performed at room temperature except for a series of experiments performed in a constant-temperature standing incubator. For these latter studies, all solutions were placed in the incubator at the desired temperature for $1 \mathrm{~h}$ before the initiation of sickling. The temperature of the effluent from the flow channel was monitored throughout the procedure with a thermistor Tele-

The only way that dithionite molecules could enter the channel at this point would be by molecular diffusion. In a 1-min time period, Eq 5 in the Appendix predicts a diffusion distance of approximately $0.06 \mathrm{~cm}$, a value which is negligible compared to the total channel length. 
Thermometer (Model 421, Yellow Springs Instrument Co., Yellow Springs, Ohio).

Conductivity experiment. Experiments were performed to obtain an estimate of the time required for the dithionite solution to reach that point on the inner surface of the flow channel where the erythrocytes under observation were located. At this point, two platinum wires, $50 \mu \mathrm{m}$ in diameter and $50 \mu \mathrm{m}$ apart, were inserted flush with the inner surface of a plastic cover slip mounted in the flow channel. The plane of the wires was perpendicular to the direction of flow. The channel was filled with $10^{-5} \mathrm{M} \mathrm{KCl}$ and the syringe and side stream valves were filled with $10^{-2} \mathrm{M} \mathrm{KCl}$. Then, flow through the channel was initiated, and the change in conductivity was determined by measuring the voltage drop across a resistor, as traced on an oscilloscope. A constant voltage source was used.

\section{RESULTS}

Sickling time ws. flow. The sickling times of individual cells were tabulated in 0.5 -s intervals after initiation of flow and "sickling histograms" were constructed. From the histograms, the time at which $50 \%$ of the initially discoidal cells had sickled (the measured $t_{50}$ ) was obtained. $S S$ cells from three patients were studied at flow rates between 0.1 and $0.3 \mathrm{ml} / \mathrm{s}$, and representative results from one of these studies are shown in Fig. 2. (Similar results based on 1- and 2-s histogram intervals were obtained from three other patients.) In Fig. 2 note that the sickling time, as reflected by the measured $t_{50}$, is essentially independent of flow for flow rates greater than approximately $0.2 \mathrm{ml} / \mathrm{s}$. Thus, at these higher flow rates, the sickling process is essentially reaction-limited; that is, the time for sickling, as determined by the measured $t_{50}$, is limited by the time re-

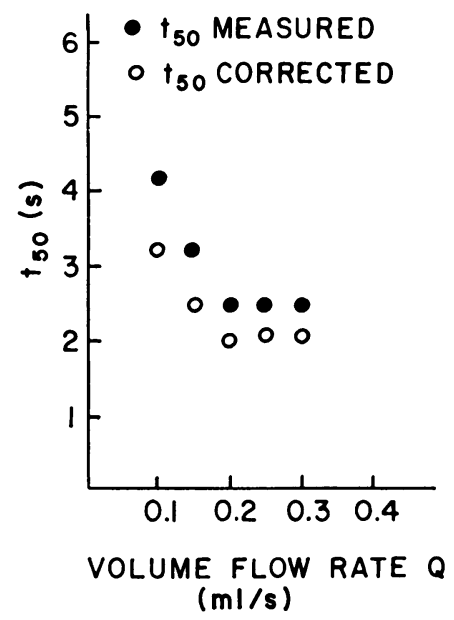

FIGURE 2 The effect of flow rate on the $t_{50}$. The volume flow rate through the channel was varied between 0.1 and $0.3 \mathrm{ml} / \mathrm{s}$ for the same sample of $S S$ cells. A histogram was constructed for the number and percentage of cells sickling per 0.5 -s interval after initiation of flow. The measured $t_{50}(\bullet)$, the time required for $50 \%$ of the cells to sickle, was obtained directly from the histogram. The corrected $t_{50}(O)$ is the measured $t_{50}$ minus the mean transit time at the particular flow rate. quired for morphologic sickling to begin and not by the time required to remove oxygen, which, of course decreases as the flow rate increases. Based on these results, a "standard" flow rate of $0.25 \mathrm{ml} / \mathrm{s}$ was chosen and all experiments were performed at this standard flow rate unless otherwise noted.

Sickling time vs. dithionite concentration. At the standard flow rate, the effect of decreasing the standard dithionite concentration $(2.5 \mathrm{~g} /$ liter $)$ was determined for $S S$ cells from three patients. In all cases, 0.5 -s histogram intervals were used. No change in the measured $t_{50}$ was observed for concentrations between 2.5 and 0.31 $\mathrm{g} /$ liter $\left(1.44 \times 10^{-2}\right.$ and $\left.1.79 \times 10^{-3} \mathrm{M}\right)$. In one experiment, the dithionite concentration was decreased to 0.125 and $0.05 \mathrm{~g} /$ liter $\left(7.18\right.$ and $\left.2.87 \times 10^{-4} \mathrm{M}\right)$, and this resulted in an increase in the measured t5o from $2.8 \mathrm{~s}$ to 4.2 and $7.1 \mathrm{~s}$, respectively.

Typical time for deoxygenation. Sickling times, measured from the initiation of flow, must be corrected for the delay in achieving deoxygenation of the channel. A corrected t $t_{50}$ could be calculated from the measured to simply by subtracting the mean transit time $(\bar{t})$ defined as the time required to replace 1 vol of fluid. At the standard flow rate of $0.25 \mathrm{ml} / \mathrm{s}, \overline{\mathrm{t}}=0.4 \mathrm{~s}$. However, at the low Reynolds numbers which occur in these experiments (at $0.25 \mathrm{ml} / \mathrm{s}$ the Reynolds number in the channel is 25), the flow is laminar and the velocity profile becomes parabolic within a short distance from the entrance and within a very short time after the initiation of flow (see Appendix). Since the velocity of the fluid near the wall where the cells are located is quite small compared to the average or mean flow velocity, diffusion perpendicular to the direction of flow is very important in determining the time required to introduce dithionite and remove oxygen from the region where the cells are located (see Appendix).

In the conductivity experiments performed at the standard flow rate, no change in the voltage drop across the electrode was observed until $0.5 \mathrm{~s}$ after the initiation of flow. At $0.53 \mathrm{~s}(1.3 \mathrm{t})$, the voltage drop measurement indicated that the $\mathrm{KCl}$ concentration was $10 \%$ of the steady state value, achieved approximately $1 \mathrm{~s}$ after initiation of flow. Thus, the time required for deoxygenation would be much longer than the mean transit time except for one very important fact: complete equilibration with the dithionite solution in the syringe is not required to attain zero $\mathrm{PO}_{2}$ at the point where the cells are located. An excess of dithionite was added to the previously deoxygenated buffer. Only a fraction of the dithionite added is required to reduce the oxygen bound to hemoglobin. The exact minimum concentration is not known, although experiments performed with $12.5 \%$ of the standard dithionite concentration resulted in sickling histograms identical to those obtained for 
the standard dithionite concentration. In addition, the approximate analysis presented in the Appendix indicates that the dithionite concentration will reach approximately $10 \%$ of the steady-state (syringe) value after $0.64 \mathrm{~s}$ of flow. Since we could not determine the precise instant at which channel deoxygenation occurs, we chose, for convenience, $\overline{\mathfrak{t}}(0.4 \mathrm{~s})$ as an approximate time for deoxygenation, and the corrected $t_{50}$ 's rather than the measured $t_{5}$ 's are reported in the results to follow.

Flicker and deformability. In all cases there was no cessation of cell membrane flicker (4) before morphologic sickling. Even for those unique $S S$ cells that required $20 \mathrm{~s}$ or more before morphologic sickling began,
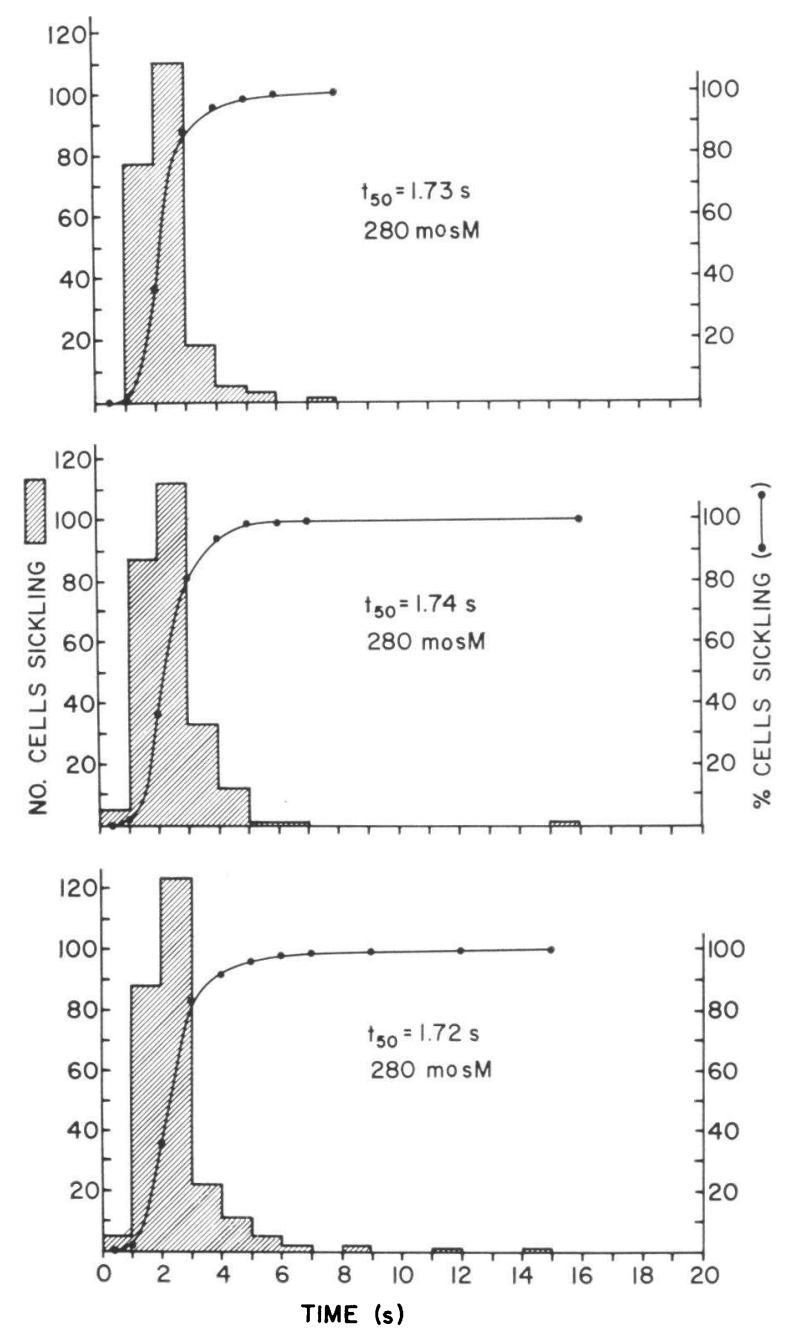

FIGURE 3 Sickling times of $S S$ erythrocytes. Each histogram represents the results of a separate loading of the flow channel with a sample of $S S$ erythrocytes prepared on the day of study and exposed to identical temperature and buffer osmolality. The $t_{50}$ shown is the corrected $t_{50}$. Experiments were performed at flow rate of $0.25 \mathrm{ml} / \mathrm{s}(\bar{t}=$ $0.4 \mathrm{~s})$.
TABLE I

The Corrected $t_{50}$ of Red Cells from Patients with Sickle Cell Anemia

\begin{tabular}{llllllll}
\hline & \multicolumn{7}{c}{ Patients } \\
\cline { 2 - 8 } Exp. & $\mathrm{A}$ & $\mathrm{B}$ & $\mathrm{C}$ & $\mathrm{D}$ & $\mathrm{E}$ & $\mathrm{F}$ & $\mathrm{G}$ \\
\hline & & & & $s$ & & & \\
1 & 1.74 & 1.60 & 2.30 & 1.70 & 3.30 & 1.52 & 2.75 \\
2 & 1.72 & 1.76 & 2.25 & 1.71 & 3.35 & 1.57 & \\
3 & 1.73 & 1.75 & 1.90 & 1.80 & & & \\
\hline
\end{tabular}

At $280 \operatorname{mos} \mathrm{M}$ and $25-27^{\circ} \mathrm{C}$.

flicker did not cease in advance of morphologic sickling. Of course, after sickling was complete, all flicker ceased. In several experiments, the flow rate was decreased by a factor of 150 so that sickling was diffusion-limited, and the time required for morphologic sickling to begin was $7-8 \mathrm{~min}$ instead of $2 \mathrm{~s}$ or less. Nevertheless, even in these cases flicker did not cease in advance of morphologic sickling. However, it was noted that in these diffusion-limited cases approximately $1 \mathrm{~s}$ was required for the completion of morphologic sickling rather than $0.5 \mathrm{~s}$. In addition, under slow deoxygenation, many more sickle forms that involve a dramatic change in morphology from the biconcave shape were observed. Rapid (reaction-limited) deoxygenation produced subtle morphological changes, primarily from a biconcave to a "holly leaf" shape.

The experiments that involved cyclical pulsations of flow also failed to demonstrate a premorphologic event. Individual cellular elongation did not change from cycle to cycle before morphologic sickling. However, this technique cannot determine subtle changes in a cell's ability to deform, if, indeed, such changes do exist.

Sickling of SS and AS erythrocytes under standard conditions. The sickling responses of samples of $S S$ and $A S$ erythrocytes suspended in and deoxygenated

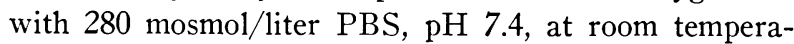
ture $\left(24-27^{\circ} \mathrm{C}\right)$ were studied. Representative histograms are presented in Figs. 3 and 4. Fig. 3 also shows that on three successive loadings of the flow channel with the same sample of $S S$ red cells, virtually identical histograms were produced. The corrected t5o values for cells from seven $S S$ patients are summarized in Table I. Typically, $50 \%$ of the originally discoidal cells sickle within $2 \mathrm{~s}$, and the variation in $t_{50}$ on repeated determinations on a sample from a single patient was less than $10 \%$. The tso values for cells from eight individuals with the trait were $12,28,50,57,64,134$, and 155 s. Determinations of both $\mathrm{MCHC}$ and percentage sickle hemoglobin were not made on all samples.

Effect of osmolality on sickling times. Erythrocytes were washed and resuspended in a buffer of the same osmolality as that used in deoxygenating the flow 


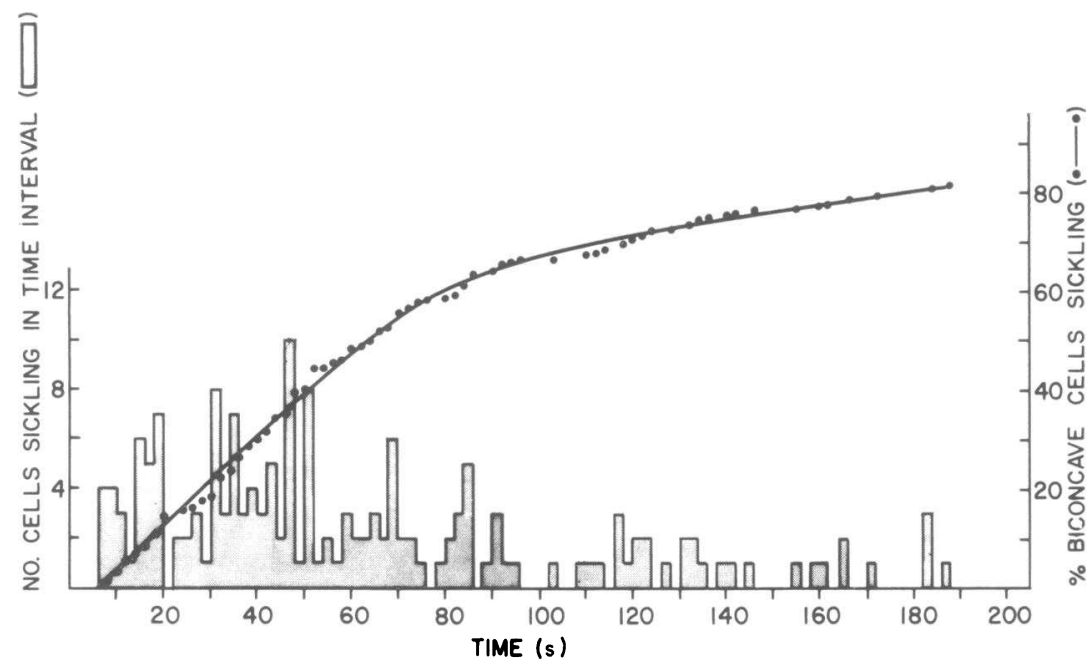

Figure 4 Sickling times of $A S$ erythrocytes. The histogram shows the number and percentage of erythrocytes sickling per 2 -s intervals.

channel. The MCHC was determined after the red cells had been resuspended in the appropriate buffer for 20 $\min$ at room temperature. Fig. 5 shows sickling histograms of $S S$ erythrocytes from the same patient, subjected to deoxygenation at three different osmolalities. With the hypotonic buffer of $200 \mathrm{mosmol} /$ liter (MCHC $=33$ ), the range of sickling times had broadened and the (corrected) tso was nearly three times the value obtained with $280 \mathrm{mosmol} / \mathrm{liter} \mathrm{PBS}(\mathrm{MCHC}=36)$. The hyperosmolar buffer produced an even shorter tio and shifted the peak sickling time to the interval between 1 and $2 \mathrm{~s}$ after initiation of flow.

Altering the osmolality of the buffer also affected the sickling times of $A S$ erythrocytes (Fig. 6). With 290 mosmol/liter PBS $(\mathrm{MCHC}=30)$ there is a wide range of sickling times. After $20 \mathrm{~s}$ of deoxygenation, less than $70 \%$ of the red cells had sickled. The hyperosmolar buffer $(\mathrm{MCHC}=33)$ produced a constricted histogram, and all cells had sickled by $8 \mathrm{~s}$ of deoxygenation.

Sickling times of SS and AS erythrocytes separated by centrifugation. The variable propensity to sickle among red cells from the same individual, exposed to the same ambient conditions, was noted by Padilla et al. (4) and is apparent in all sickling histograms. Since sickling times were affected by osmotically induced changes in $\mathrm{MCHC}$, density separation by centrifugation was used to obtain fractions with different sickling times.

The sickling times of top, middle, and bottom fractions of a sample of $S S$ erythrocytes are shown in Fig. 7. Bottom cells sickled faster than top cells. The MCHC's of the top, middle, and bottom fractions were 28,33 , and 51 , respectively. The concentration of ISC's in the bottom fraction $(30 \%)$ contributed to the high $\mathrm{MCHC}$ of that fraction.
Subpopulations of a sample of $A S$ erythrocytes demonstrated marked differences in the time of sickling (Fig. 8), with t5o's of 267,108 , and $29 \mathrm{~s}$ for the top, middle, and bottom fractions, respectively. The corresponding MCHC's were 26, 28, and 31. The percentage of sickle hemoglobin was the same in all three fractions.

Effect of $p H$ on sickling times. Fig. 9 shows sickling histograms (note the 2-s histogram interval) of $S S$ red cells from the same patient, deoxygenated with buffers of four different $\mathrm{pH}$ values and the same osmolality (285 mosm PBS). Before deoxygenation, the cells were equilibrated with the appropriate solution for at least 30 min. The most marked difference in sickling times occurred in the sample at $\mathrm{pH} 7.6$. The same $S S$ erythrocytes were deoxygenated with 200 and 280 mosm PBS at different $\mathrm{pH}$ 's. Between $\mathrm{pH} 6.6$ and 7.0 the $\mathrm{t}_{50}$ was little changed, whereas, beyond $\mathrm{pH} 7.0$ a progressive increase in tso was observed.

Effect of temperature on sickling times. A washed sample of $S S$ erythrocytes was resuspended in 200 mos$\mathrm{mol} /$ liter and $280 \mathrm{mosmol} / \mathrm{liter} \mathrm{PBS}$ and subsequently deoxygenated at $13^{\circ}, 18^{\circ}, 23^{\circ}, 29^{\circ}$, and $34^{\circ} \mathrm{C}$. Fig. 10 shows that the $t_{50}$ decreased as the temperature increased. However, this temperature effect was greatly accentuated in the cells sickling in hypotonic medium. At $23^{\circ} \mathrm{C}$ the t5o of cells in hypotonic medium was approximately one-fifth of the $t_{50}$ at $13^{\circ} \mathrm{C}$; whereas, the cells in isotonic medium experienced only a reduction in tso of one-half for the same temperature changes.

The relationship between temperature and osmotically induced changes in $\mathrm{MCHC}$ is also manifest in the sickling times of trait cells (Fig. 11). The same sample of $A S$ cells was deoxygenated at three different buffer osmolalities and three different temperatures. As the buffer osmolality increased, the relative changes in tso 
between two temperature points is diminished. In addition, the temperature increase from $18^{\circ}$ to $27^{\circ} \mathrm{C}$ produced a much greater decrease in tso than the increase from $27^{\circ}$ to $34^{\circ} \mathrm{C}$.

\section{DISCUSSION}

At the flow rates employed in these studies, sickling times were independent of flow rate and, therefore, were not biased in the direction of longer times, as would occur in a diffusion-limited system. As a reaction-limited process, sickling consists of at least two major processes : the conversion of hemoglobin from the oxygenated to the deoxygenated state and the subsequent gelation of hemoglobin molecules into long fibers. Since the deoxy-
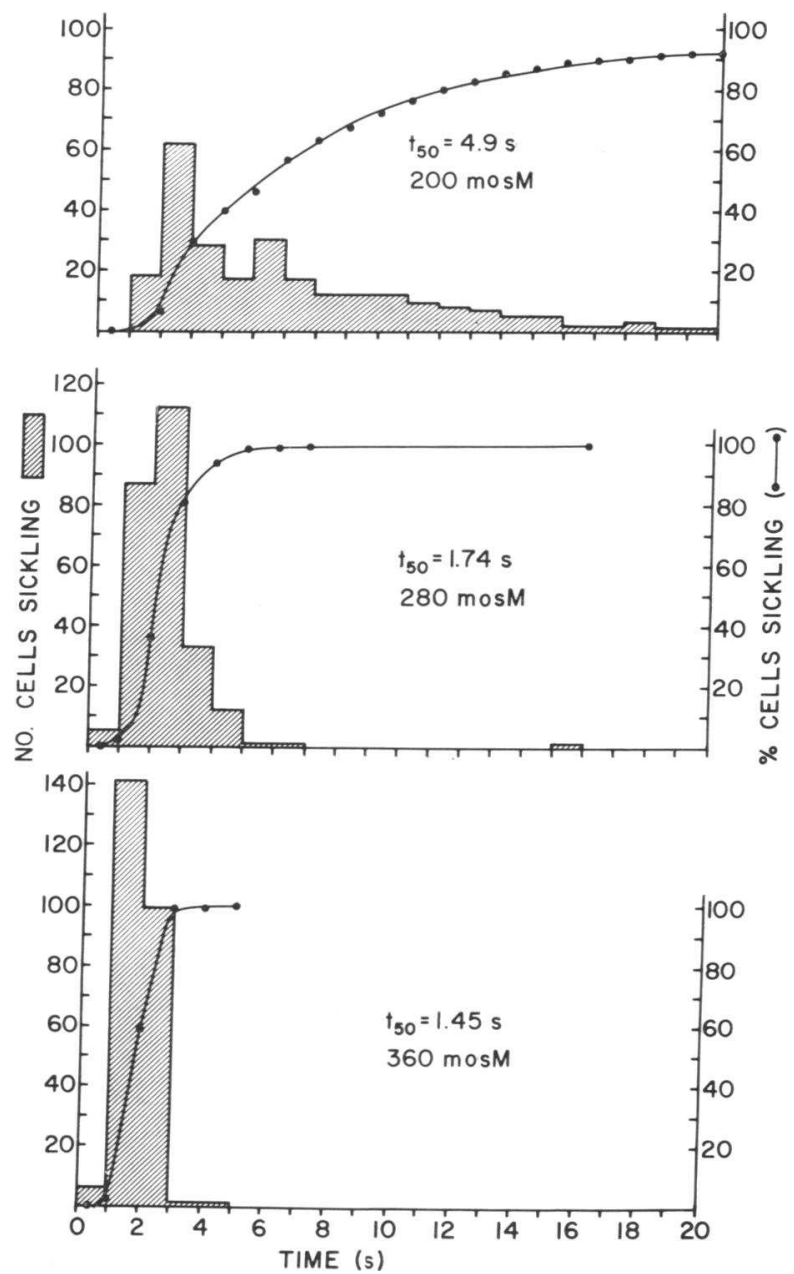

FIGURE 5 The effect of osmolality on sickling times of $S S$ erythrocytes. A sample of $S S$ erythrocytes was washed and deoxygenated with dithionite-PBS buffers of indicated osmolality. The number of cells sickling per time interval was counted. Time is measured from the initiation of flow. The $t_{50}$ indicated is the time required for $50 \%$ of the cells to sickle, corrected for a mean transit time through the flow channel of $0.4 \mathrm{~s}$.

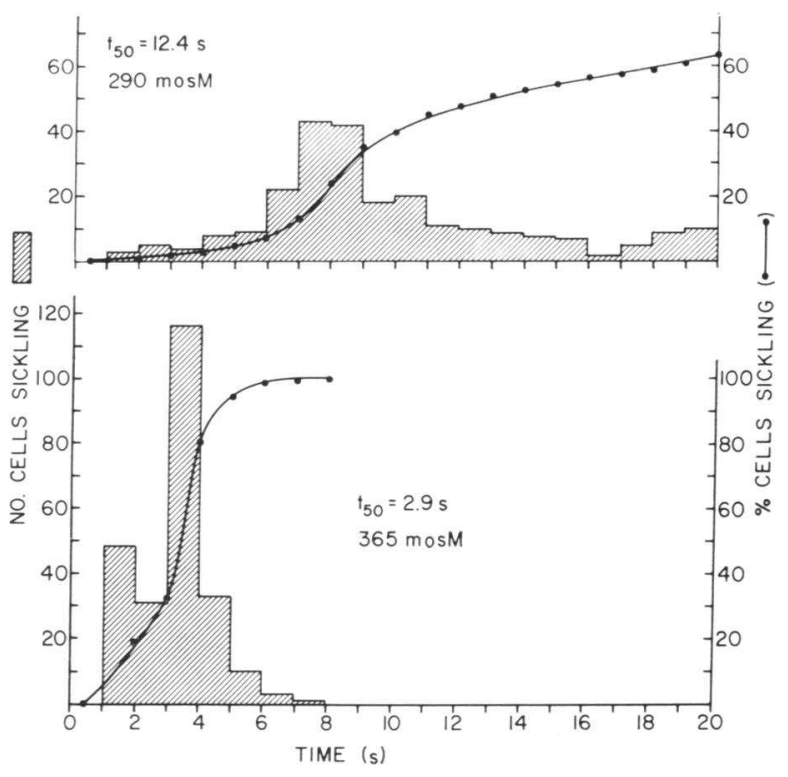

FIGURE 6 The effect of osmolality on sickling times of $A S$ erythrocytes.

genation process with dithionite solutions and suspensions of whole cells is extremely rapid $(12,13)$ with half times (as estimated from an Arrhenius plot) of approximately $0.1 \mathrm{~s}$ at $25^{\circ} \mathrm{C}\left(0.04 \mathrm{~s}\right.$ at $\left.37^{\circ} \mathrm{C}\right)$, and since the typical tso for sickling at $25^{\circ} \mathrm{C}$ is approximately $2 \mathrm{~s}$, it is apparent that the gelation of sickle hemoglobin is the rate-limiting process in the sickling phenomenon.

The onset of cell deformation was used to identify the sickling event. In another study of sudden deoxygenation of sickle erythrocytes with dithionite solutions, Messer and Harris (5) suggested that altered rheologic behavior precedes morphologic sickling. Their conclusion was based on the reduction in filtration through Millipore filters within $0.12 \mathrm{~s}$ after deoxygenation. The data on filtration, however, might be interpreted differently. Even in the fully oxygenated state, $85 \%$ of cells from patients with sickle cell anemia did not pass through the filter. Hence, the filtration behavior of only $15 \%$ of the cells was measured. After $0.12 \mathrm{~s}$ of exposure to dithionite and a collection period of $5 \mathrm{~s}$, filtration recovery was reduced to $2 \%$. Although the exposure to dithionite was $0.12 \mathrm{~s}$ before the cells entered the filter, the collection period of $5 \mathrm{~s}$ during continuous flow is sufficient to permit sickling of some of the initially retained cells. Retained cells that were initially deformable might possibly allow other cells to slip by, but once they sickled, filterability would be affected. Thus, the altered filterability might represent increased blockage of the filter meshwork by retained cells with fast sickling times. The situation is analogous to fixing cells with glutaraldehyde after they have entered the filter.

Sickling Times of Erythrocytes 


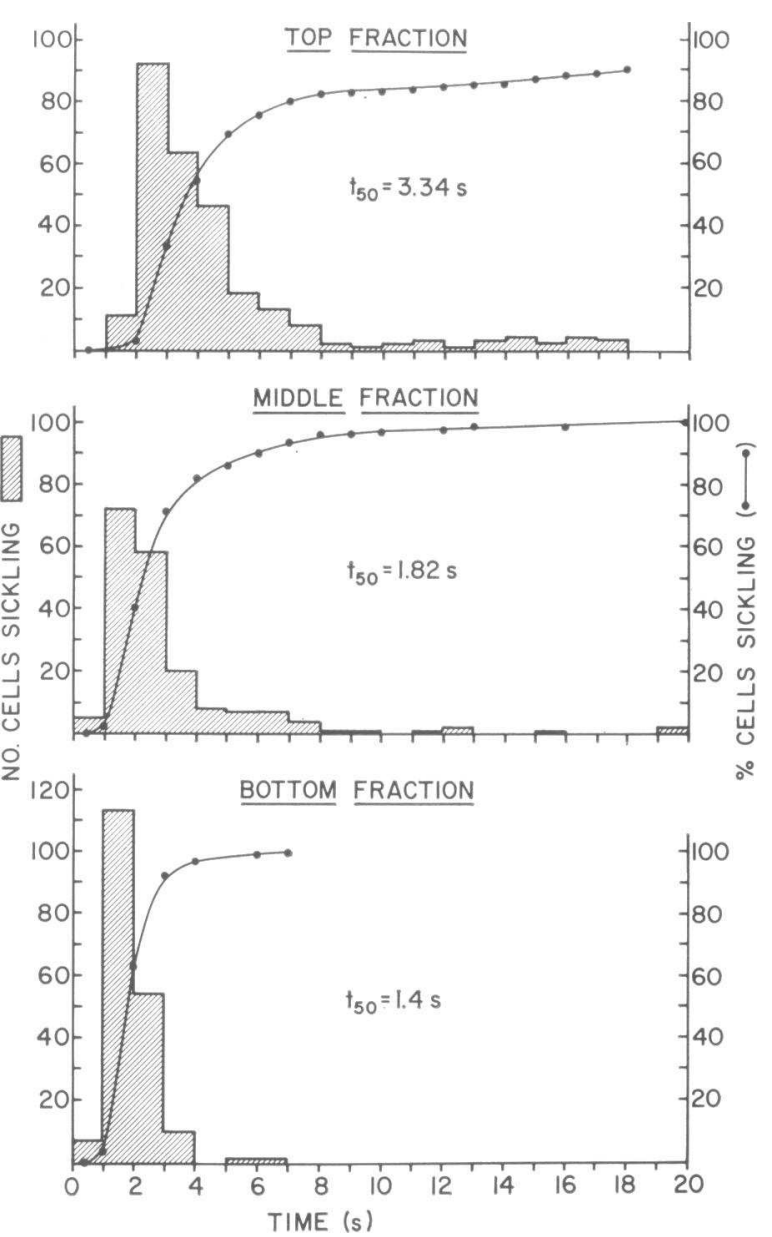

FIGURE 7 The sickling times of SS erythrocytes separated by density fractionation. A sample of $S S$ erythrocytes was separated into top, middle, and bottom fractions after centrifugation.

Rampling and Sirs (6) also used dithionite to deoxygenate sickle cells rapidly. However, in contrast to the fixation procedure employed in the Messer-Harris experiment, the cells in the Rampling-Sirs experiment underwent fixation during very rapid flow. In fact, in their experiments they observed a "background" of deformed cells that comprised approximately $30 \%$ of the sample. The fluid shear stress produced by such a highspeed flow, whether laminar or turbulent, will produce very dramatic cell deformations ranging from "trilobular" to ellipsoidal $(14,15)$. (However, it should be noted that evidence, in disagreement with that cited here $[6,14,15]$, indicates that no cellular deformation occurs in a rapid-reaction apparatus [16]). It would be difficult to distinguish between morphologic alterations due to sickling and that due to fluid shear stress. Nevertheless, Rampling and Sirs detected an increase, relative to the $30 \%$ background of deformed cells, of "bizarre-shaped" cells. This increase began at $0.03 \mathrm{~s}$ after deoxygenation and this lag time did not vary with tem- perature for temperatures between $18^{\circ}$ and $37^{\circ} \mathrm{C}$. After this extremely small lag time, there was a steady increase with time in the number of deformed cells. Both the extremely short lag time and the steady increase with time are difficult to explain in view of our observations. Even at the molecular level, sickling appears to be characterized by a very long latent or lag phase, followed by rapid gelation (17-19). Perhaps the high-speed turbulent flow in the Rampling-Sirs experiment produces violent agitation of the intracellular hemoglobin which, in turn, induces rapid aggregation or polymerization during what would otherwise be a quiescent, pregelation phase.

The other evidence for a premorphologic alteration is the observation by Padilla et al. (4) that disappearance of the "flicker" phenomenon precedes cell deformation. The flicker phenomenon is seen in normal erythrocytes and is presumed to reflect movement of the membrane due to undefined forces. Loss of flicker was felt to represent aggregation of membrane-associated

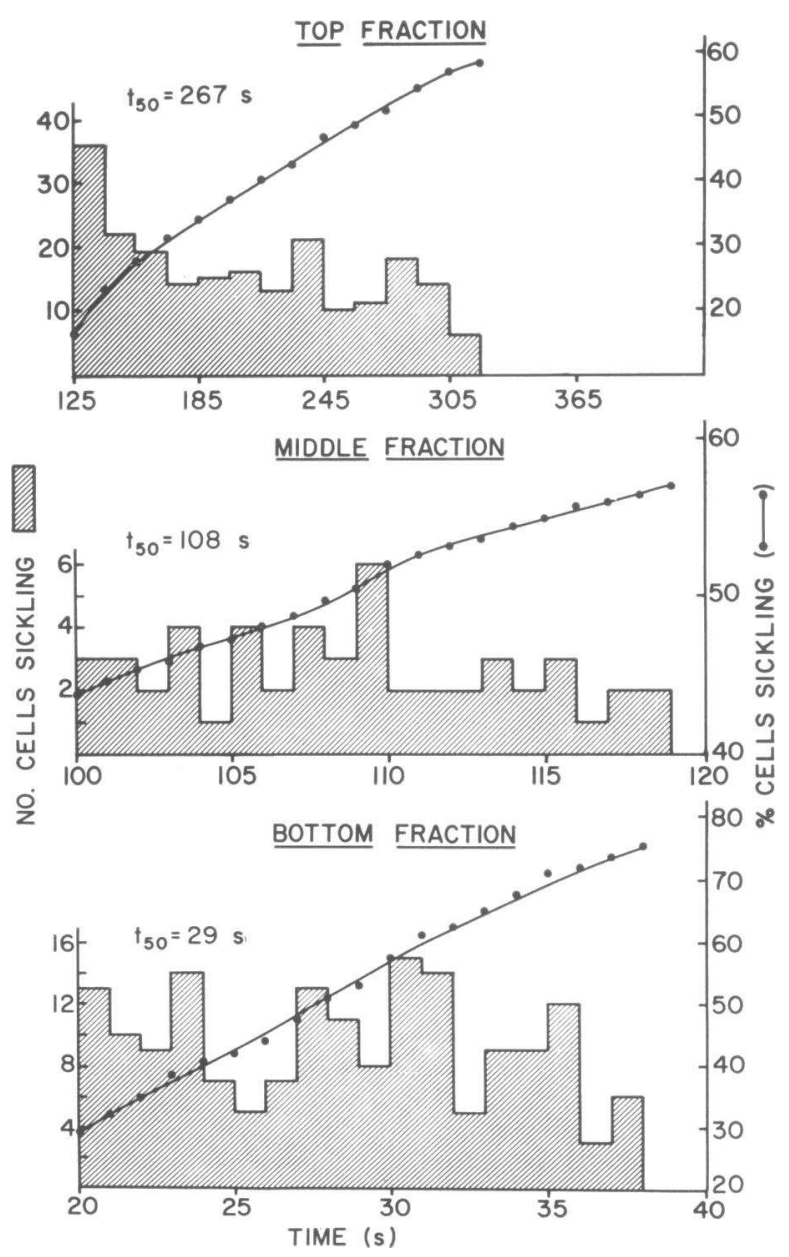

FIGURE 8 The sickling times of $A S$ erythrocytes separated by density fractionation. 


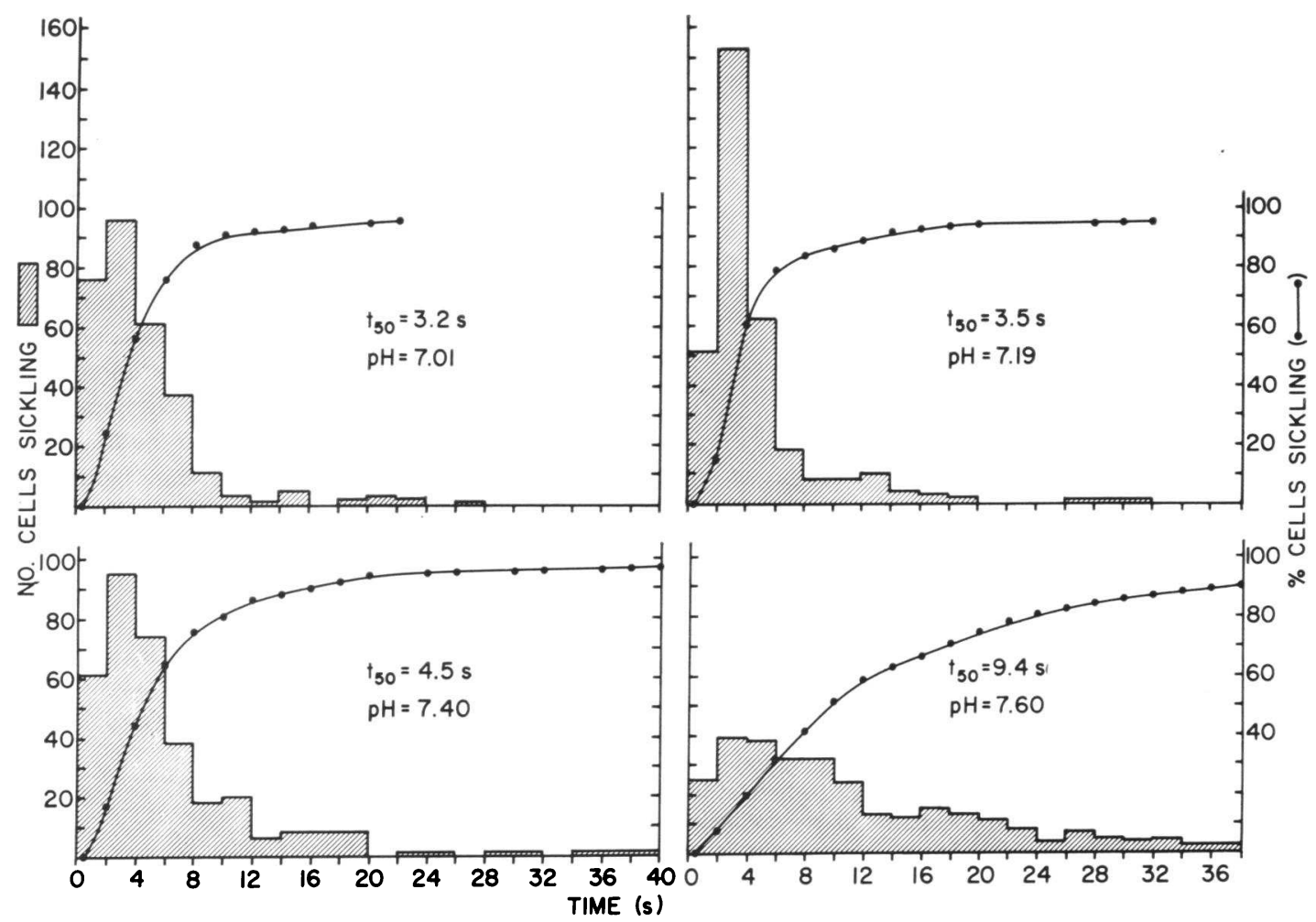

FIGURE 9 The effect of $\mathrm{pH}$ on the sickling times of $S S$ erythrocytes. A sample of $S S$ erythrocytes was washed and deoxygenated with dithionite-PBS buffers of indicated $\mathrm{pH}$. Note the use in the figure of 2-s histogram intervals.

hemoglobin, and thereby an early manifestation of the sickling process. We have observed the flicker phenomenon during deoxygenation under a variety of conditions. Flicker persisted up to the time of complete cell deformation, even though cell deformation required approximately $0.5 \mathrm{~s}$ for completion during rapid deoxygenation.

Subtle changes in red cell deformability or internal viscosity may precede the morphologic event that we have used as the cellular index of gelation of sickle hemoglobin. However, from our observations of periodic cell deformation and sickling during flow oscillation, cells exhibit normal deformation until morphologic sickling begins. Thus, we conclude that erythrocyte sickling is a two-step process. During the first step, or lag period, the viscosity of the hemoglobin solution inside the cell is unaltered since the cell's ability to deform is unaltered. For $S S$ cells the first step is on the order of $2 \mathrm{~s}$. In the second step, cell deformation occurs and is completed within $0.5 \mathrm{~s}$, approximately an order of magnitude faster than the first step. The lag time between deoxygenation and the onset of morphologic sickling is analogous to the initial slow prenucleation or pregelation phase of purified sickle hemoglobin (17-19), and the actual duration of cell deformation corresponds to the rapid process of gelation.
Bookchin et al. (20) observed that the reduction in erythrocyte sickling at higher $\mathrm{pH}$ was independent of the $\mathrm{pH}$ effect on the oxygen affinity of hemoglobin. Our studies demonstrate that $\mathrm{pH}$ can also alter the time required for individual cells to sickle. Under the conditions of rapid deoxygenation with dithionite, it is unlikely that the observed effect of $\mathrm{pH}$ on sickling times was due to changes in the kinetics of hemoglobin desaturation. The sharp increase in to when cells were deoxygenated in buffer at $\mathrm{pH}$ greater than 7.4 suggests that the resultant alterations in the charge of amino acids disturb the interactions which promote sickling. Although the data suggest that alkalosis would be beneficial in aborting painful crises, a recent controlled clinical trial failed to demonstrate the efficacy of alkali therapy (21).

Buffer osmolality was a potent factor in altering the

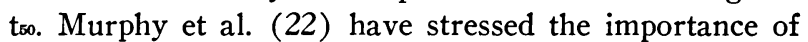
the associated decrease in intracellular $\mathrm{pH}$ when the $\mathrm{MCHC}$ is increased by exposure to $\mathrm{NaCl}$. Based on their data, the maximum change in $\mathrm{MCHC}$ in our studies would result in less than 0.05 increase in $\mathrm{pH}$. Is the MCHC the major determinant of the tso for the osmotically altered cells, as well as for the density-separated cell fractions? A number of factors could account 


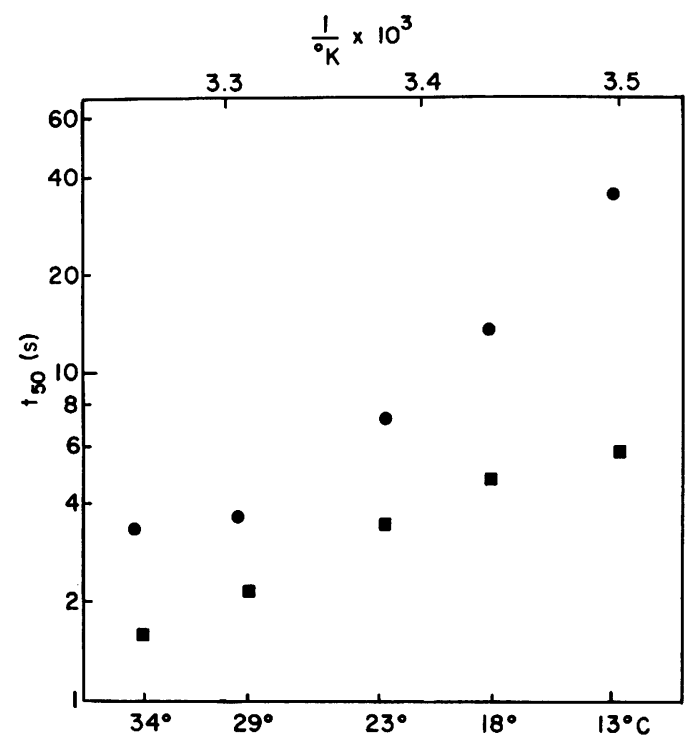

FIGURE 10 The effect of temperature and osmolality on the corrected $t_{50}$ of $S S$ erythrocytes. A sample of $S S$ cells was washed and deoxygenated with two dithionite-PBS buffers, $200 \operatorname{mos} M(\bullet)$ and $280 \operatorname{mos} M(\mathbb{E})$. Each study was performed in a standing room incubator at the indicated temperature. The corrected to is plotted on a logarithmic scale, and the temperature and the inverse of the absolute temperature are shown on the abscissa.

for the marked differences among the cell fractions. However, since the fetal hemoglobin content of the SS sample was low, one would not expect large differences among the fractions. Furthermore, Seakins et al. (23) found no significant differences in fetal hemoglobin levels between top and bottom fractions. In the $A S$ study fetal hemoglobin is not an important variable. 2-3 diphosphoglycerate (2-3 DPG) might be expected to decrease the sickling time due to its stabilization of the deoxy conformation (24). However, the slowest sickling occurred in the top fraction, which has the highest concentration of 2-3 DPG (23).

The kinetics of gelation of sickle hemoglobin solutions show an exquisite sensitivity to the sickle hemoglobin concentration. The delay time has been reported to be dependent on the concentration to at least the 4th (17), 15th (18), or 30th (19) power. From calculations from the top and middle histograms in Figs. 7 and 8, it was found that the too depended on MCHC to the 4th and 12th powers, respectively. Although our results are consistent with the observations on gelation kinetics, factors other than MCHC may contribute to the tso differences among cell factions and osmotically altered cells.

Malfa and Steinhardt (17) found that the latent period for aggregation of sickle hemoglobin solutions was markedly temperature-dependent. Deoxygenated hemoglobin solutions initially at $2^{\circ} \mathrm{C}$ were warmed to temperatures between $13.6^{\circ}$ and $25^{\circ} \mathrm{C}$. The first detectable increase in viscosity occurred after a latent period of several minutes for the sample warmed to $25^{\circ} \mathrm{C}$, whereas the latent period was more than $14 \mathrm{~h}$ for the sample raised to $13.6^{\circ} \mathrm{C}$. From calorimetric and optical studies of hemoglobin solutions subjected to a step change in temperature, Hofrichter et al. (19) have also identified a delay time that is strongly temperature-dependent. They report that a $1^{\circ} \mathrm{C}$ temperature rise in the range $20-30^{\circ} \mathrm{C}$ almost halves the delay time. It must be emphasized that the greatest hemoglobin concentration at which these and similar gelation studies were performed was $23.3 \mathrm{~g} / 100 \mathrm{ml}$. This sickle hemoglobin concentration is far below that present in the red cells of $S S$ patients. Our studies indicate that hemoglobin concentration (as modified by osmotically induced alterations in $\mathrm{MCHC}$ ) is very important in the expression of a temperature effect. At lower sickle hemoglobin concentrations, as in $A S$ erythrocytes or $S S$ erythrocytes suspended in hypotonic buffer, the sickling times were greatly accelerated by increases in temperature (i.e., there is a high "apparent" activation energy). How-

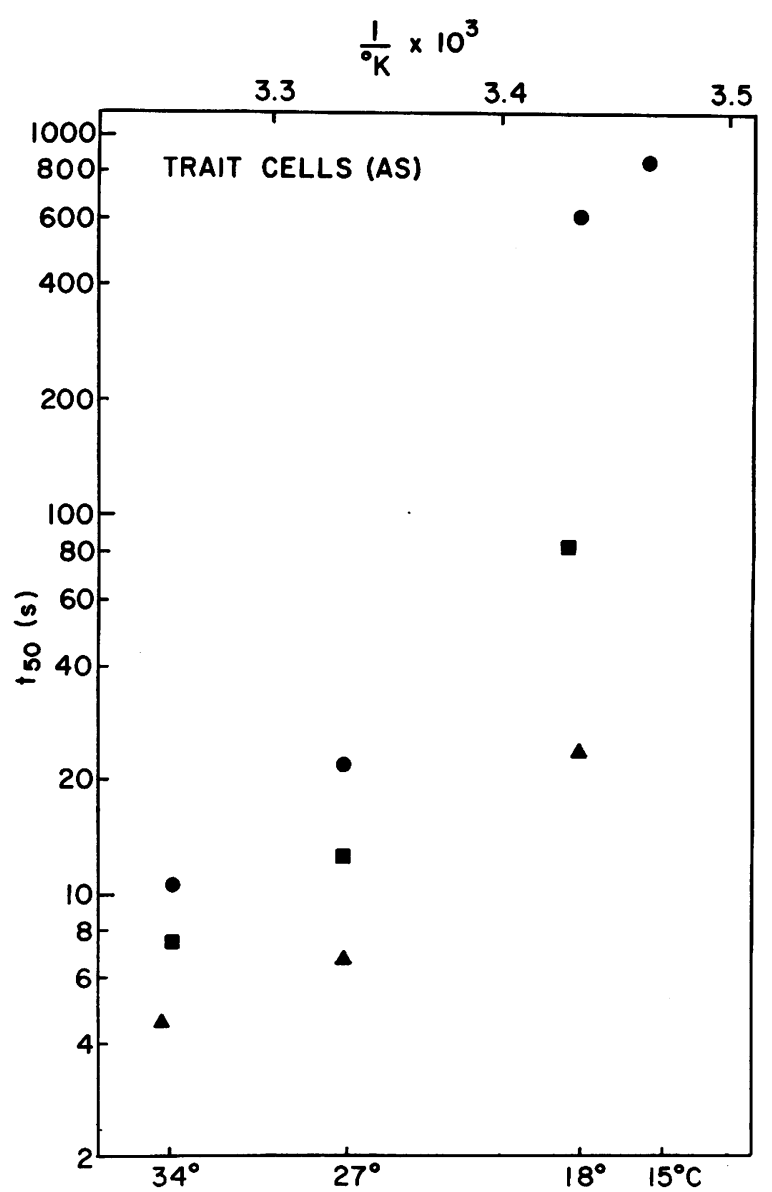

Figure 11 The effect of temperature and osmolality on the corrected t50 of $A S$ erythrocytes. $\bullet, 280$ mosM;, 320 $\operatorname{mos} \mathrm{M} ; \mathrm{A}, 360 \operatorname{mos} \mathrm{M}$. 
ever, the MCHC of $S S$ cells in isotonic buffer and the osmotically induced high MCHC's of $A S$ cells dampened the magnitude of the effect of elevated temperature on sickling times (i.e., the apparent activation energy was less). Overall, the apparent activation energies calculated from the $t_{50}$ measurements ranged from approximately 70 to $10 \mathrm{kcal} / \mathrm{mol}$. In the more precise measurements made with dilute hemoglobin solutions, activation energies as high as $90 \mathrm{kcal} / \mathrm{mol}$ have been reported (19). The concentration of sickle hemoglobin within the $S S$ red cell may be such an overwhelming factor in determining the cell's sickling behavior that the properties of dilute solutions may not always be applicable to the physiologic situation.

The monitoring of individual red cells has highlighted the variable propensity of red cells from the same individual to sickle under identical ambient conditions. It is apparent from the histograms that among $S S$ or $A S$ red cells from the same individual, there are wide differences in the lag period. Some cells can remain at zero $\mathrm{Po}_{2}$ for extended periods of time before sickling occurs. If the kinetics of sickling at zero Poz are applicable at physiologic Poz's, then the duration of the lag period could determine the cell's fate. Obviously in vivo red cells are not subjected to rapid, total deoxygenation. Nonetheless, those cells that require longer time periods to sickle regardless of ambient $\mathrm{PO}_{2}$ would have a better chance of passing through the microcirculation in a deformable, unsickled state.

We agree with Hofrichter et al. (19) that in considering new drugs in the treatment of sickle cell disease, it might be important to develop agents that retard the sickling times of cells, rather than reduce the extent of sickling at steady-state conditions. It is also possible that concentrations of anti-sickling agents, which have little effect on the extent of sickling, could have a major effect on sickling kinetics, and thus be beneficial therapeutically with less toxicity.

\section{APPENDIX}

\section{Momentum and mass transfer calculations}

Start-up time. When the volume flow rate is suddenly changed from zero flow to some finite value, the velocity profile that results will initially be blunt or flat, except at the wall where the velocity is zero. This "plug-flow" velocity profile will eventually develop into a parabolic profile within some characteristic time period $t_{o}$. An estimate for $t_{o}$ is given by the characteristic time required for momentum (or mass or energy) to diffuse through some characteristic distance $h$, which is the channel halfwidth. Thus. $t_{0}=h^{2} / \nu$, where $\nu$ is the kinematic viscosity of water (25). For $h=250 \mu \mathrm{m}$ and $\nu=0.01 \mathrm{~cm}^{2} / \mathrm{s}, t_{o}$ is $0.06 \mathrm{~s}$. Since this time is much less than the mean transit time of $0.4 \mathrm{~s}$ at the standard flow rate, the time-dependent deviation from the steady-state parabolic profile can be neglected.

Entrance length. When fluid with a blunt velocity profile enters a channel, a finite distance or "entrance length" is required before the velocity profile assumes its charac- teristic parabolic shape. An expression for this entrance length, $l$, is given by $l=0.16 Q h / 2 W \nu$, where $Q$ is the volume flow rate and $W$ is the channel width (26). For $Q=0.25 \mathrm{~cm}^{3} / \mathrm{s}, h=250 \mu \mathrm{m}, W=0.95 \mathrm{~cm}, \quad$ and $\nu=0.01$ $\mathrm{cm}^{2} / \mathrm{s} ; l$ is $0.05 \mathrm{~cm}$. Since the entrance length is much less than the distance from the entrance to the point where the cells are located $(2 \mathrm{~cm})$, the length-dependent deviation from the steady-state parabolic profile can be neglected.

Typical time for deoxygenation. From the above consideration, it is clear that the velocity profile in the channel is essentially parabolic for all time and distance. Thus,

$$
v_{x}^{\prime}=\frac{3}{2}\left(\frac{Q}{2 W h}\right)\left[1-\left(\frac{y}{h}\right)^{2}\right]
$$

where $i^{\prime} x$ is the velocity in the $\mathrm{x}$-direction parallel to the two channel surfaces, $y$ is the perpendicular distance measured from the center plane of the channel; and $Q, W$, and $h$ are as defined above.

From Eq. 1 it is obvious that an expression for the advancement with time $t$ of the leading "edge" of the dithionite "wave front" is given by

$$
x=\frac{3}{2} t\left(\frac{Q}{2 W h}\right)\left[1-\left(\frac{y}{h}\right)^{2}\right]
$$

as long as diffusion of the dithionite relative to the wave front is neglected. Since $x=L$ at the point where the cells are located and since $\bar{t}$ (the mean transit time) $\equiv V / Q=$ $2 W L h / Q$, Eq. 2 can be written as

$$
\frac{y}{h}=\left(1-\frac{2}{3} \frac{\bar{t}}{t}\right)^{\frac{1}{2}} ; \stackrel{t}{\bar{t}} \geq \frac{2}{3} .
$$

Eq. 3 describes the advance of the dithionite "plane" wave front towards the cells if no diffusion could occur. (Note that when $(t / \bar{t})>1$, approximately, Eq. 2 can be approximated by a straight line (plane) at $x=L$ and that diffusion will cause a "smearing" of this line).

The diffusion of a substance in a direction perpendicular to a plane of constant concentration $C_{0}$ is given by

$$
C_{o}^{C}=1-\operatorname{erf}\left[y^{\prime} / 2(D t)^{\frac{1}{2}}\right]
$$

where "erf" denotes the error function and $D$ is the diffusivity (25). The expression is valid when there is no disappearance of the substance because of a chemical reaction. However, only a very small percentage of dithionite will be removed by chemical reaction with dissolved oxygen because an excess amount of dithionite was added to the deoxygenating solution $\left(1.44 \times 10^{-2} \quad \mathrm{M} \quad \mathrm{Na}_{2} \mathrm{~S}_{2} \mathrm{O}_{4}\right.$ compared to $2.43 \times 10^{-4} \mathrm{M}$ dissolved oxygen).

In Eq. $4, C / C_{0}=0.10(10 \%)$ when

$$
\frac{y^{\prime}}{2(D t)^{\frac{1}{2}}}=1.16 \text { or } \frac{y^{\prime}}{h}=2.32 \frac{(D t)^{\frac{1}{2}}}{h}
$$

Adding Eq. 5 to Eq. 3 will provide an approximate correction for the effect of diffusion:

$$
\frac{y+y^{\prime}}{h} \approx\left(1-\frac{2}{3} \frac{\bar{t}}{t}\right)^{\frac{1}{2}}+2.32 \frac{(D t)^{\frac{1}{2}}}{h}
$$

where $y+y^{\prime}$ denotes the point where the dithionite concentration has decreased to appreximately $10 \%$ of that in the syringe. When $\left(y+y^{\prime}\right) / h=1$, the $10 \%$ dithionite solution will reach the cells. In this case, Eq. 6 gives a value for $t$ of $0.64 \mathrm{~s}$ when $\bar{t}=0.40 \mathrm{~s}, h=250 \mu \mathrm{m}$, and $D=10^{-5}$ $\mathrm{cm}^{2} / \mathrm{s}^{3}$ Note that the $10 \% \mathrm{KCl}$ solution reached the elec- 
trodes after $0.53 \mathrm{~s}$ of flow, which gives a good agreement with the theoretical calculation.

Once the dithionite solution reaches the cells, oxygen must diffuse from the cells before they can sickle. For this case, a typical time for diffusion is given by

$$
\frac{\delta}{\left(4 D_{o} \tau\right)^{\frac{1}{2}}}(1+M)^{\frac{1}{2}}=1 \text { or } \tau=\frac{(1+M) \delta^{2}}{4 D_{o}}
$$

where $\delta$ is a typical distance, $M$ is the dimensionless slope of the oxygen saturation curve (the change in oxyhemoglobin concentration with dissolved oxygen concentration) and $D_{0}$ is the diffusion of oxygen in hemoglobin (27). For $\delta=1 \mu \mathrm{m}, D_{o}=10^{-5} \mathrm{~cm}^{2} / \mathrm{s}$, and $M=250$ (its maximum value, which gives the largest value for $\tau$ ); $\tau$ is $0.06 \mathrm{~s}$. Since the mean transit time is $0.4 \mathrm{~s}$ and the sickling time is approximately $2 \mathrm{~s}$, the diffusion of oxygen from the cells is essentially instantaneous.

\section{ACKNOWLEDGMENTS}

We thank M. Drummond, J. Reinhardt, J. Stevens, and T. Gottipati for their excellent technical assistance.

This work was supported by contract NO1-HB-22934 from the Sickle Cell Disease Branch of the National Heart and Lung Institute. Preliminary studies were supported by a grant (NS-06833) from the National Institutes of Health.

${ }^{3}$ Estimates for $D$ ranging from 0.8 to $1.0 \times 10^{-5} \mathrm{~cm}^{2} / \mathrm{s}$ were obtained from Eq. 16.5-9 of Bird et al. (25) by assuming that the molecular weight of the reacting species varied from 128 to 96 and that the molar volume of the solute was numerically equal to its molecular weight.

\section{REFERENCES}

1. Ponder, E. 1945. The sickling phenomenon and its bearing on the problem of red cell structure. J. Exp. Biol. $21: 77-83$.

2. Allison, A. G. 1956. Observations on the sickling phenomenon and on the distribution of different haemoglobin types in erythrocyte populations. Clin. Sci. (Oxf.). 15: 497-510.

3. Charache, S., and C. L. Conley. 1964. Rate of sickling of red cells during deoxygenation of blood from persons with various sickling disorders. Blood. 24: 25-48.

4. Padilla, F., P. A. Bromberg, and W. N. Jensen. 1973 The sickle-unsickle cycle: A cause of cell fragmentation leading to permanently deformed cells. Blood. 41: 653660.

5. Messer, M. J., and J. W. Harris. 1970. Filtration characteristics of sickle cells: Rates of alteration of filterability after deoxygenation and reoxygenation, and correlations with sickling and unsickling. J. Lab. Clin. Med. 76: 537-547.

6. Rampling, M. W., and J. A. Sirs. 1973. The rate of sickling of cells containing sickle-cell haemoglobin. Clin. Sci. Mol. Med. 45: 655-664.

7. Singer, K., A. I. Chernoff, and L. Singer. 1951. Studies on abnormal hemoglobins. I. Their demonstration in sickle cell anemia and other hematologic disorders by means of alkali denaturation. Blood. 6: 413-428.

8. Murphy, J. R. 1973. Influence of temperature and method of centrifugation on the separation of erythrocytes. J. Lab. Clin. Med. 82: 334-341.

9. Hochmuth, R. M., and N. Mohandas. 1972. Uniaxial loading of the red-cell membrane. J. Biomech. 5: 501509.

10. Hochmuth, R. M., N. Mohandas, and P. L. Blackshear, Jr. 1973. Measurement of the elastic modulus for red cell membrane using a fluid mechanical technique. Biophys. J. 13: 747-762.

11. Evans, E. A. 1973. New membrane concept applied to the analysis of fluid shear- and micropipette-deformed red blood cells. Biophys. J. 13: 941-954.

12. Bauer, C., R. A. Klocke, D. Kamp, and R. E. Forster. 1973. Effect of 2,3-diphosphoglycerate and $\mathrm{H}^{+}$on the reaction of $\mathrm{O}_{2}$ and hemoglobin. Am. J. Physiol. 224: 838-847.

13. Roughton, F. J. W. 1964. Transport of oxygen and carbon dioxide. Handb. Physiol. Section 3: respiration. $1: 767-825$.

14. Goldsmith, H. L., and J. Marlow. 1972. Flow behaviour of erythrocytes. I. Rotation and deformation in dilute suspensions. Proc. R. Soc. Lond. B. Biol. Sci. 182: 351-384.

15. Sutera, S. P., and M. H. Mehrjardi. 1975. Deformation and fragmentation of human red blood cells in turbulent shear flow. Biophys. J. 15 : 1-10.

16. Miyamoto, Y., and W. Moll. 1972. The diameter of red blood cells when flowing through a rapid reaction apparatus. Respir. Physiol. 16: 259-266.

17. Malfa, R., and J. Steinhardt. 1974. A temperature-dependent latent-period in the aggregation of sickle-cell deoxyhemoglobin. Biochem. Biophys. Res. Commun. 59: 887-893.

18. Moffat, K., and Q. H. Gibson. 1974. The rates of polymerization and depolymerization of sickle cell hemoglobin. Biochem. Biophys. Res. Commun. 61: 237-242.

19. Hofrichter, J., P. D. Ross, and W. A. Eaton. 1974. Kinetics and mechanism of deoxyhemoglobin $\mathrm{S}$ gelation: a new approach to understanding sickle cell disease. Proc. Natl. Acad. Sci. U. S. A. 71: 4864-4868.

20. Bookchin, R. M., R. L. Nagel, and T. Balazs. 1974. Oxygen affinity-independent effects of $\mathrm{pH}$ on sickling and gelation. J. Clin. Invest. 53: 9a. (Abstr.)

21. Cooperative Urea Trials Group. 1974. Therapy for sickle cell vasoocclusive crises. Controlled clinical trials and cooperative study of intravenously administered alkali. JAMA (J. Am. Med. Assoc.). 228: 1129-1131.

22. Murphy, J. R., M. Wengerd, and R. W. Kellermeyer. 1974. Erythrocyte $\mathrm{O}_{2}$ affinity: influence of cell density and in vitro changes in hemoglobin concentration. $J$. Lab. Clin. Med. 84: 218-224.

23. Seakins, M., W. N. Gibbs, P. F. Milner, and J. F. Bertles. 1973. Erythrocyte hg-s concentration. An important factor in the low oxygen affinity of blood in sickle cell anemia. J. Clin. Invest. 52: 422-432.

24. Finch, J. T., M. F. Perutz, J. F. Bertles, and J. Döbler. 1973. Structure of sickled erythrocytes and of sickle-cell hemoglobin fibers. Proc. Natl. Acad. Sci. U. S. A. 70: 718-722.

25. Bird, R. B., W. E. Stewart, and E. N. Lightfoot, Jr. 1960. Transport phenomena. John Wiley \& Sons, Inc., New York. 8, Tables 1.1-1; pp. 503 and 539.

26. Schlichting, H. 1968. Boundary-layer theory. McGrawHill Book Company, New York. 6th edition. 178.

27. Lightfoot, E. N., Jr. 1974. Transport phenomena and living systems. John Wiley \& Sons, Inc., New York. 212-216. 